\title{
Seasonal Health Risks Due to Zoonotic Pathogens from Hand-dug Well Water in Ohangwena and Omusati Regions of Namibia
}

\author{
Billy McBenedict ${ }^{1,2 *}$, Wilhelmina Ndapunikwa Hauwanga ${ }^{1,3}$, Heike Wanke ${ }^{4}$, \\ Percy Maruwa Chimwamurombe ${ }^{5}$ (D) and Bernard Mudenda Hang'ombe ${ }^{2}$
}

${ }^{1}$ School of Public Health, Department of Environmental and Occupational Health, University of Namibia, P.O. Box 2654, Eliander Mwatale Street, Oshakati West, Namibia. ${ }^{2}$ Microbiology Unit, School of Veterinary Medicine, University of Zambia, P. O. Box 32379, Lusaka, Zambia. ${ }^{3}$ Department of Natural Resource Management, Namibia University of Science and Technology, P/Bag 13388, 13 Storch Street, Windhoek, Namibia. ${ }^{4}$ Geology Department, University of Namibia, 340 Mandume Ndemufayo Avenue, Windhoek, Namibia. ${ }^{5}$ Department of Natural and Applied Sciences, Namibia University of Science and Technology, P/Bag 13388, 13 Storch Street, Windhoek, Namibia.

\begin{abstract}
Water is a global need for the health and survival of all life forms and a habitat to some. However, approximately one billion people in developing countries do not have access to safe drinking water in which Namibia is not an exception. Rural communities of Ohangwena and Omusati regions of Namibia construct hand-dug wells as a source of water. However, these hand-dug wells are not monitored for water quality and are generally poorly constructed. In addition, these hand-dug wells are easily accessed by both humans and animals making them a potential reservoir for zoonotic bacteria partly known to aid antimicrobial resistance development, a global health concern. A metagenomics analysis targeting the 16S rRNA gene was used to detect the bacterial communities in a total of 40 hand-dug well water samples, with 20 being from the wet season and the rest from the dry season. A total of $\mathbf{5 7}$ bacterial pathogens were detected with a diverse of zoonotic assemblage. Analysis revealed significant differences in diversity and evenness, and no significant difference in richness of zoonotic bacterial pathogens in hand-dug wells between the wet and dry seasons $(P<0.05)$ with the dry season having a higher diversity and evenness compared to the wet season. The analysis showed that the hand-dug well water was not definitely safe for human and livestock consumption and their exposure to zoonotic pathogens was pronounced in the dry season.
\end{abstract}

Keywords: Bacteria, Diversity, Hand-dug wells, Metagenomics, Water, Zoonotic.

*Correspondence: bmcbenedict@unam.na; +264813667923

(Received: 12 April 2019; accepted: 30 May 2019)

Abbreviations: AMR: Antimicrobial resistance; OTU: Operational taxonomic units; $\mathrm{H}^{\prime}$ : Shannon-Wiener diversity; D: Simpson diversity; R: Richness; E: Evenness; UTI: urinary tract infections; PCR: Polymerase Chain Reaction.

Citation: Billy McBenedict, Wilhelmina Ndapunikwa Hauwanga, Heike Wanke, Percy Maruwa Chimwamurombe, and Bernard Mudenda Hang'ombe, Seasonal Health Risks Due to Zoonotic Pathogens from Hand-dug Well Water in Ohangwena and Omusati Regions of Namibia, J Pure Appl Microbiol., 2019; 13(3): 1583-1593. https://doi.org/10.22207/JPAM.13.3.31

(c) The Author(s) 2019. Open Access. This article is distributed under the terms of the Creative Commons Attribution 4.0 International License which permits unrestricted use, sharing, distribution, and reproduction in any medium, provided you give appropriate credit to the original author(s) and the source, provide a link to the Creative Commons license, and indicate if changes were made. 


\section{INTRODUCTION}

Water is a universal need for survival across all life forms and serves as a habitat to some creatures. Although important, water can be a source and driver of diseases to humans and livestock if contaminated and this highlights the need to ensure the safety of drinking water supplies. However, approximately one billion people in developing countries do not have access to safe drinking water in which Namibia is not an exception. ${ }^{1}$ The safety and quality of drinking water sources are a global concern especially in rural areas where water scarcity and contamination can be alarming. Odonkor and Addo $^{2}$ argued that rural areas of developing countries experience high rates of waterborne diseases compared to other ailments due to bacteriological contamination. The water shortages in developing countries have led to communities depending on the use of groundwater to supplement the surface water supplies. Since groundwater microbial water quality assessment is not prioritised in most developing countries, water related diseases account for $10 \%$ of the disease burden in developing countries. ${ }^{3}$

Rural communities of Ohangwena and Omusati regions within the Cuvelai Etosha Basin (CEB) of Namibia construct hand-dug wells as a primary source of water. However, these handdug wells are not monitored for water quality and are generally poorly constructed. This increases the likelihood of incidences of severe endemic water borne diseases and possess a public health threat. Moreover, shallow perched aquifers are not appropriate water resources for human consumption due to high vulnerability to contamination. ${ }^{4}$ General observed description of hand-dug well aspects that potentiate contamination include plant materials that grow inside the walls of hand-dug wells, birds and small mammals that die in hand-dug wells, and when faecal matter gains entry. This potentially provides carbon deposits to bacterial communities in handdug wells thereby supporting growth since carbon is known to be among the principle determinants of microbial growth. ${ }^{5}$

Since hand-dug wells form part of freshwater environments which are known to be a habitat for microbial life, it is likely that the general status of the hand-dug wells in Ohangwena and
Omusati regions possess variable resources and conditions that promote microbial growth and pose a health risk to consumers. Hand-dug well water can be a habitat for pathogenic viruses, bacteria, fungi and protozoa to both humans and livestock leading to death in severe cases. ${ }^{6,7}$ This water resource can also be a reservoir for zoonotic bacteria which is currently an emerging global health concern. Zoonotic diseases are infectious diseases that can be transmitted between vertebrate animals and humans with or without an arthropod intermediate. ${ }^{8}$

Zoonotic bacterial pathogens are problematic because they can aid the development and transfer of antimicrobial resistance..$^{9}$ This resistance is known partly to be the result of inappropriate use of antibiotics in animal husbandry and agriculture. Hence the detection of zoonotic pathogens in water used for both humans and livestock consumption serves as a sentinel surveillance for possible antimicrobial resistance gene reservoirs. This is especially of concern when abundant zoonotic bacteria are detected with $E$. coli species which are known to possibly be a source, assimilator and disseminator of AMR plasmids/genes from the environment. ${ }^{10}$ This study investigated the seasonal health risks to humans and livestock of consuming none sanitised hand-dug well water in Ohangwena and Omusati regions of Namibia using metagenomics detection of zoonotic bacterial pathogens. Metagenomics provides detailed information regarding the bacterial communities in a habitat compared to the culture based approaches by bypassing limitations of culturing based methods that lead to the inability to quantify the total natural diversity within a given habitat.

\section{METHODS}

\section{Study sites and sample collections}

The study investigated hand-dug wells in rural Omusati and Ohangwena regions of Namibia. These hand-dug wells ranged in depth from shallow which could allow animal entry to deep with a depth of at least $18 \mathrm{~m}$. Fig. 1 and 2 shows the general structure of the hand-dug wells found in the Omusati and Ohangwena regions of Namibia. The sampling strategy employed was convenience sampling which targeted the areas in which hand-dug wells were monitored for 
hydrochemical water quality by The Southern African Science Service Centre for Climate Change and Adaptive Land Management. A total of 40 water samples were collected in sterile $200 \mathrm{ml}$ bottles from the hand-dug wells, half the total number were collected from the wet and 20 from the dry season respectively. The same hand-dug wells were assessed in both the wet and dry seasons. The water samples were collected by lowering a rope tied to the sterile bottles into the hand-dug wells, and subsequently transported on ice to the University of Namibia for analysis. Preceding transportation, the temperature of the water was measured.

DNA extraction and 16S rRNA gene amplification

Water samples containing each a volume of $200 \mathrm{ml}$ were centrifuged at a speed of $7000 \mathrm{xg}$ for 1 hour in order to concentrate the bacteria. Each of the sample volumes were then reduced to $10 \mathrm{ml}$ after centrifugation by disposing the supernatant. DNA was extracted using SEEPREP 12 ${ }^{\mathrm{TM}}$ kit (Seegene, Rockville, USA), and the respective concentrations and quality were determined by the NanoDrop-2000 spectrophotometer (NanoDrop Technologies, Wilmington, DE). The 16S rRNA gene was amplified using $P C R$ with universal primer sets 27F (5' AGAGTTTGATCMTGGCTCAG $3^{\prime}$ ) and 1492R (5' TACGGYTACCTTGTTACGACTT $\left.3^{\prime}\right)$. The thermo-cycler (Bio-Rad, Hercules, CA) was used with reaction conditions of; 1 cycle of pre-denaturation at $94^{\circ} \mathrm{C}$ for 4 minutes, 35 cycles of denaturation at $94^{\circ} \mathrm{C}$ for 1 minute, annealing at $55^{\circ} \mathrm{C}$ for 30 seconds, an extension at $72^{\circ} \mathrm{C}$ for 2 minutes, and a final extension at $72^{\circ} \mathrm{C}$ for 10 minutes. Next generation sequencing and diversity assay using Illumina $16 \mathrm{~S}$ sequencing of the amplicons was performed at Mr. DNA Next Generation Sequencing provider in Texas, United States of America.

\section{PCR product preparation and sequencing}

The amplified amplicons were then prepared for sequencing as described by the Illumina TruSeq DNA library preparation protocol. Sequencing (20k 2x300bp Illumina 16s) was performed at MR. DNA (www.mrdnalab.com, Shallowater, TX, USA) on a MiSeq using the manufacturer's guidelines, and further processing of sequence data was done using a proprietary analysis pipeline (MR. DNA, Shallowater, TX, USA).

\section{S rRNA Metagenomics data collection and analysis}

The Metagenomics sequence data attained from Mr. DNA Next Generation Sequencing provider (Texas, United States of America) was processed and edited using a proprietary analysis pipeline (www.mrdnalab.com, MR. DNA, Shallowater, TX). The Q25 sequence data derived from the sequencing process were depleted of barcodes and primers, and short sequences less than 150 bp were removed. In addition, sequences with ambiguous base calls, and homopolymer runs exceeding $6 \mathrm{bp}$ were removed. The sequences were then denoised and chimeras also removed. Operational taxonomic units (OTUs) were defined after removal of singleton sequences, and clustering at $3 \%$ divergence ( $97 \%$ similarity) was performed as described by Capone et al. ${ }^{11}$ OTUs were then taxonomically classified by performing a BLASTn against a curated GreenGenes, RDPII (http://rdp.cme.msu.edu) and NCBI (www.ncbi. nlm.nih.gov) databases and compiled into each taxonomic level according to DeSantis et al. ${ }^{12}$ The files were compiled based on counts and percentages with counts revealing the actual number of sequences while the percentages displayed the relative proportion (in percentage) of sequences within each sample that map to the designated taxonomic classification. Hence, the bacterial communities and the percentage of each species in the community were explored.

\section{Construction of a phylogenetic tree}

Selection of cleaned zoonotic bacterial sequences from the total identified OTU's, was performed. A phylogenetic tree was then constructed using the Maximum Likelihood Method. ${ }^{13}$ Only the trees with the highest log likelihood were chosen and percentages of trees in which the associated taxa clustered together were shown next to the branches. Initial tree(s) for the heuristic search were obtained automatically by applying the Neighbor-Join and BioNJ algorithms to a matrix of pairwise distances estimated using the Maximum Composite Likelihood (MCL) approach, and then selecting the topology with superior log likelihood value. Bootstrap was performed and the consensus trees inferred from 1000 replicates were taken to represent the evolutionary history of the taxa analysed..$^{14}$ Branches corresponding to 
Table 1. Wilcoxon rank test performed to determine the influence of season on the abundance of the detected zoonotic bacterial pathogens

\begin{tabular}{|c|c|c|}
\hline Bacterial species & $Z$ value & $P$ - Value \\
\hline Actinomyces spp. & -0.938 & 0.348 \\
\hline Actinomyces viscosus & -1.34 & 0.180 \\
\hline Aerococcus viridans & -2.65 & 0.008 \\
\hline Afipia sp. & -2.92 & 0.004 \\
\hline Alcaligenes faecalis & -3.92 & 0.000 \\
\hline Alcaligenes sp. & -1.84 & 0.066 \\
\hline Anabaena spp. & -1.00 & 0.317 \\
\hline Anaerorhabdus spp. & -1.00 & 0.317 \\
\hline $\begin{array}{l}\text { Anaplasma } \\
\text { phagocytophilum }\end{array}$ & -1.34 & 0.180 \\
\hline Arcobacter butzlerii & -2.03 & 0.042 \\
\hline Arcobacter cryaerophilus & -3.93 & 0.000 \\
\hline Arcobacter spp. & -1.76 & 0.079 \\
\hline Bacillus pumilus & -3.93 & 0.000 \\
\hline Bacillus spp. & -3.81 & 0.000 \\
\hline Bacillus subtilis & -3.20 & 0.001 \\
\hline Bordetella sp. & -3.92 & 0.000 \\
\hline Brucella spp. & -2.81 & 0.005 \\
\hline Chlamydia spp. & -2.21 & 0.027 \\
\hline Clostridium perfringens & -2.06 & 0.039 \\
\hline Clostridium spp. & -2.30 & 0.022 \\
\hline Corynebacterium spp. & -3.93 & 0.000 \\
\hline $\begin{array}{l}\text { Corynebacterium } \\
\text { urealyticum }\end{array}$ & -3.44 & 0.001 \\
\hline Dietzia maris & -1.69 & 0.092 \\
\hline Dietzia spp. & -3.47 & 0.001 \\
\hline Enterobacter cloacae & -2.12 & 0.034 \\
\hline Enterococcus sp. & -3.84 & 0.000 \\
\hline Erysipelothrix spp. & -0.35 & 0.726 \\
\hline Escherichia coli & -1.34 & 0.180 \\
\hline Fusobacterium nucleatum & -1.60 & 0.109 \\
\hline Fusobacterium spp. & -3.22 & 0.001 \\
\hline Hafnia sp. & -3.92 & 0.000 \\
\hline Helicobacter spp. & -0.923 & 0.356 \\
\hline Klebsiella sp. & -1.34 & 0.180 \\
\hline Legionella spp. & -2.69 & 0.007 \\
\hline Leptospira interrogans & 0.000 & 1.000 \\
\hline Leptospira spp. & -3.21 & 0.001 \\
\hline Mycobacterium spp. & -3.37 & 0.001 \\
\hline Mycoplasma sp. & -3.23 & 0.001 \\
\hline Nocardia nova & -1.34 & 0.180 \\
\hline Paenibacillus polymyxa & -1.73 & 0.083 \\
\hline Paenibacillus spp. & -3.31 & 0.001 \\
\hline Porphyromonas spp. & -2.24 & 0.025 \\
\hline Propionibacterium acnes & -2.56 & 0.011 \\
\hline Pseudomonas aeruginosa & -1.00 & 0.317 \\
\hline Pseudomonas spp. & -3.21 & 0.001 \\
\hline Rhodococcus spp. & -1.63 & 0.102 \\
\hline Rickettsia spp. & -1.72 & 0.086 \\
\hline
\end{tabular}

\begin{tabular}{lll} 
Salmonella enterica & -3.43 & 0.001 \\
Sphingobium paucimobilis & -1.60 & 0.109 \\
Sphingobium spp. & -3.08 & 0.002 \\
Sphingomonas spp. & -0.728 & 0.467 \\
Staphylococcus epidermidis & -3.58 & 0.000 \\
Staphylococcus spp. & -3.83 & 0.000 \\
Stenotrophomonas spp. & -3.20 & 0.001 \\
Treponema spp. & -0.445 & 0.656 \\
Vibrio spp. & -1.99 & 0.046 \\
Waddlia sp. & -1.34 & 0.180 \\
\hline
\end{tabular}

partitions reproduced in less than $70 \%$ bootstrap replicates were collapsed and the percentage of replicate trees in which the associated taxa clustered together in the bootstrap test (1000 replicates) were also indicated next to the branches. The evolutionary analyses were conducted in MEGA $7^{14}$ The $B$. anthracis sequence with accession number $A J 516943.1$ was retrieved from the NCBI website and used as the outgroup to root the zoonotic pathogen's phylogenetic tree. Influence of season on zoonotic bacterial pathogens abundance, diversity, evenness and richness

The distribution of the zoonotic bacterial pathogens in the wet and dry seasons was evaluated by entering the data into SPSS version 24 and subsequently generating the Shapiro-Wilk test and Kolmogorov-Smirnov test values, visually inspecting histograms, Normal Q-Q Plots, and calculation of Z scores from Skewness and Kurtosis. A Wilcoxon test was then performed to investigate the influence of season on the abundance of the identified zoonotic bacterial pathogens. The ecological concepts of species diversity and species evenness were used in this study to investigate the seasonal health risk possed to humans and livestock in consumption of unsanitized hand-dug well water. Zoonotic bacterial species richness, evenness, and both the Shannon-Wiener diversity indices and Simpson's diversity indices were calculated as described by Pielou. ${ }^{15}$ Following a normality test, a Paired sample t-test was used to investigate statistically significant differences on Shannon-Wiener diversity indices and species richness data between the wet and dry seasons while a Wilcoxon test was used for the same purpose on Simpson's diversity indices and species evenness data between the wet and dry seasons. 


\section{RESULTS}

\section{Zoonotic pathogens phylogenetic tree}

A total of 57 zoonotic pathogens were detected. The relationship between the detected zoonotic pathogens was investigated by generating a phylogenetic tree (Fig. 3). It was disclosed that $E$. cloacae, Klebsiella sp., Hafnia sp., E. coli, S. enterica and Vibrio spp. formed a cluster at $79 \%$ bootstrap. A. faecalis, Alcaligenes sp. and Bordetella sp. formed a cluster at $100 \%$ bootstrap while $P$. aeruginosa and Pseudomonas spp. formed a cluster at $96 \%$ bootstrap. Chlamydia spp. and Waddlia sp. formed a cluster at $82 \%$ bootstrap while $A$. butzleri, A. cryaerophilus and Arcobacter spp. formed a cluster at $95 \%$ bootstrap, and Anaerorhabdus spp. and Erysipelothrix spp. formed a cluster at $97 \%$ bootstrap. P. polymyxa and Paenibacillus spp. formed a cluster at $80 \%$ bootstrap while $B$. pumilus and $B$. subtilis formed a cluster at $84 \%$ bootstrap. Anabaena spp., Rhodococcus spp., Actinomyces spp., P. acnes, $A$. viscosus, Mycobacterium spp. N. nova, Corynebacterium spp., C. urealyticum, D. maris and Dietzia spp. formed a cluster at $73 \%$ bootstrap while the rest did not form any clusters. The $B$. anthracis sequence with accession number AJ516943.1 was retrieved from the NCBI website and used as the outgroup to root the zoonotic pathogen's phylogenetic tree.

Influence of season on zoonotic bacterial pathogens abundance, diversity, evenness and richness

The Kolmogorov-Smirnov and ShapiroWilk tests revealed that zoonotic pathogens data was not normally distributed $(P<0.05)$.

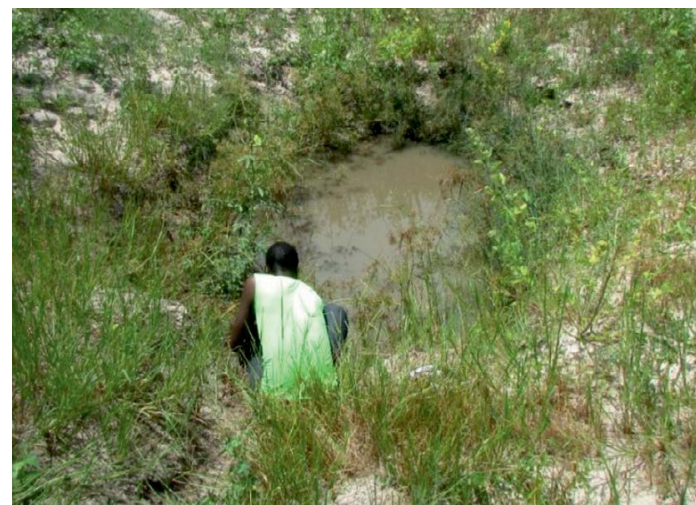

Fig. 1. An illustrative diagram of the shallow hand-dug wells found in the Ohangwena and Omusati regions of Namibia in which animals have access to the water.
Wilcoxon rank test was performed to determine the influence of season on the abundance of the detected zoonotic bacterial pathogens (Table 1). Notable pathogens; Brucella spp., Bacillus spp., Chlamydia spp., Enterococcus sp., Legionella spp., Leptospira spp., Mycobacterium spp., Salmonella enterica and Staphylococcus spp. showed a significant difference in abundance between the wet and dry season $(P<0.05$, Table 1). Brucella spp., Bacillus spp., Chlamydia spp., Enterococcus sp., Legionella spp. and Salmonella enterica had higher abundances in the dry season compared to the wet season. Leptospira spp., Mycobacterium spp. and Staphylococcus spp. had higher abundances in the wet season compared to the dry season. However, there was no significant difference in the abundance of Escherichia coli, Helicobacter spp., Treponema spp. and Klebsiella $s p$. between the wet and dry seasons.

Shannon-Wiener diversity indices and species richness data were normally distributed $(P>0.05)$ as per Kolmogrov-Smirnov test, and a subsequent Paired sample t-test disclosed a significant difference between Shannon-Wiener diversity $\left(\mathrm{H}^{\prime}\right)$ indices, and no significant difference in species richness of the detected zoonotic bacterial pathogens between the wet and dry seasons (Table 2). Simpson diversity indices and species evenness data were not normally distributed $(P<0.05)$ as per Kolmogrov-Smirnov test and a subsequent Wilcoxon rank test disclosed a significant difference in Simpson diversity (D) and evenness data between the wet and dry seasons.

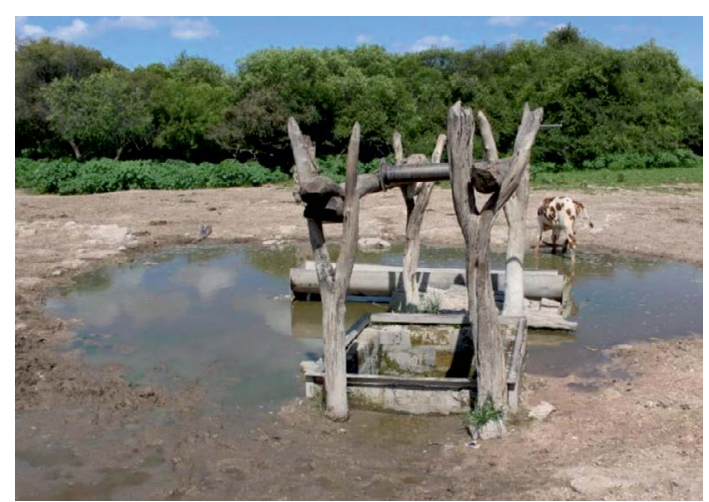

Fig. 2. An illustrative diagram of the deep hand-dug wells found in the Ohangwena and Omusati regions showing potential seepage of surrounding water into the hand-dug wells. 


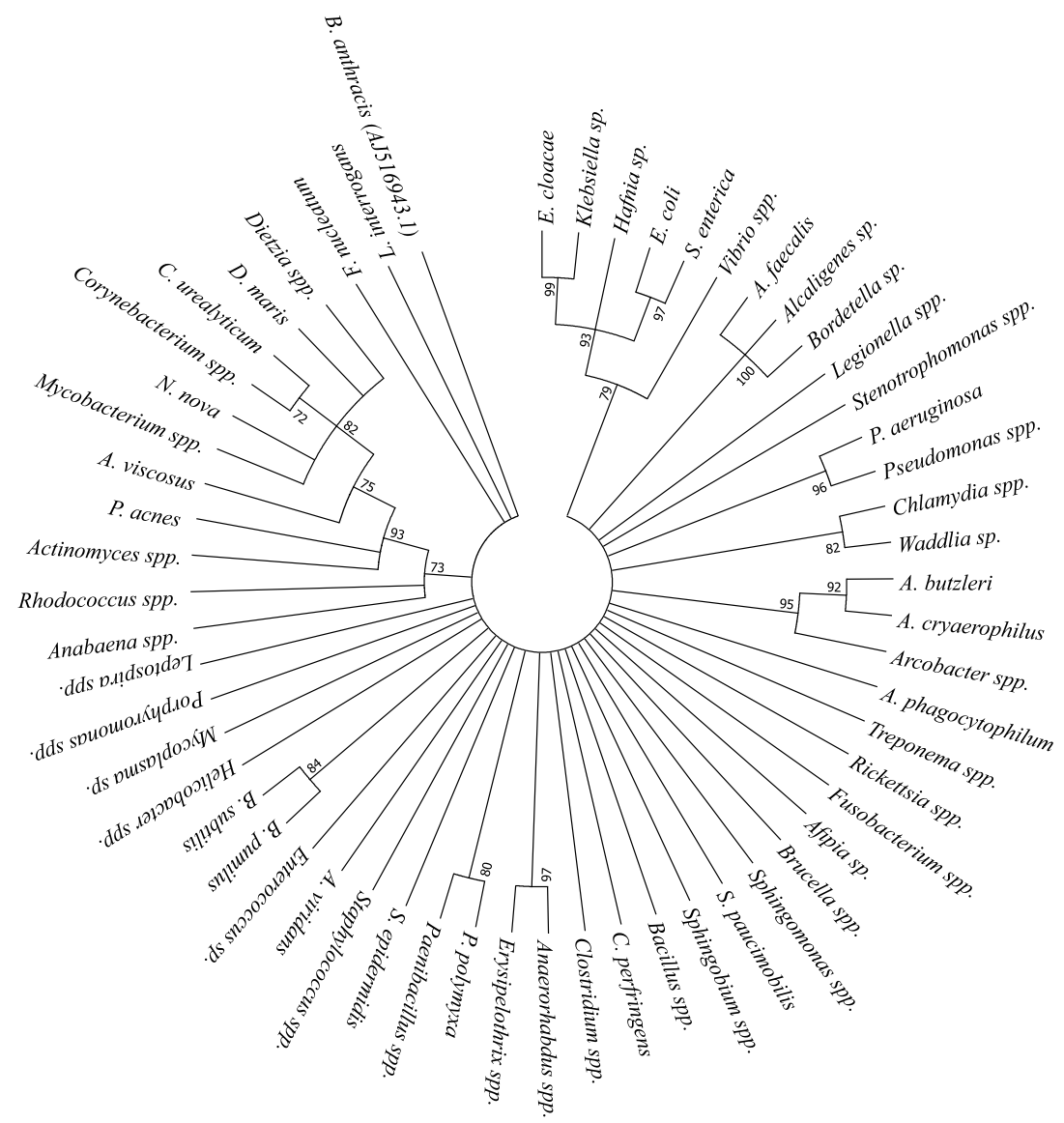

Fig. 3. Phylogenetic tree depicting the evolutionary history of the detected zoonotic bacterial pathogens. Branches corresponding to partitions reproduced in less than $70 \%$ bootstrap replicates were collapsed.

Table 2. Tests performed to determine the influence of season on human bacterial species richness (R), evenness (E) and diversity [Shannon $\left(\mathrm{H}^{\prime}\right)$ and Simpson (D)]

\begin{tabular}{|c|c|c|c|c|c|c|c|c|}
\hline \multirow[b]{2}{*}{ Parameters } & \multicolumn{4}{|c|}{ Wet season } & \multicolumn{4}{|c|}{ Dry season } \\
\hline & $\mathrm{H}^{\prime}$ & $\mathrm{D}$ & $\mathrm{R}$ & $E$ & $\mathrm{H}^{\prime}$ & $\mathrm{D}$ & $\mathrm{R}$ & $E$ \\
\hline Mean & 1.15 & 0.532 & 22.9 & 0.101 & 2.08 & 0.713 & 24.75 & 0.252 \\
\hline St.Dev & 0.564 & 0.253 & 2.67 & 0.0373 & 0.717 & 0.136 & 4.54 & 0.0990 \\
\hline $\begin{array}{l}\text { Test } \\
\text { statistics } \\
\text { value }\end{array}$ & -3.823 & -2.128 & -1.386 & -3.808 & -3.823 & -2.128 & -1.386 & -3.808 \\
\hline Df & 19 & & 19 & & 19 & & 19 & \\
\hline P-value & $P<0.05$ & $P<0.05$ & $P>0.05$ & $P<0.05$ & $P<0.05$ & $P<0.05$ & $P>0.05$ & $P<0.05$ \\
\hline
\end{tabular}

\section{DISCUSSION}

Health risks of detected zoonotic bacterial pathogens

Most clusters of the zoonotic pathogens phylogenetic tree were formed by species belonging to the same family indicating their close relation. The detection of multiple species in each family and their close relation confirmed the complexity and versatility of families. Among others, the notable zoonotic pathogens of public health concern were; Brucella spp. known to cause Brucellosis. ${ }^{16} B$. anthracis causes anthrax ${ }^{17}$ while Chlamydia abortus and Chlamydia psittaci from the genus Chlamydia may cause abortion and psittacosis respectively in animals, birds and humans. ${ }^{18} \mathrm{E}$. faecalis and E. faecium belonging to 
the genus Enterococcus can cause mastitis and bacteraemia in humans and livestock. ${ }^{19}$

Escherichia coli is known to cause diarrhoea, haemorrhagic colitis, haemolytic uremic syndrome, thrombotic thrombocytopenic Purpura, urinary tract infections, bacteraemia, wound infections, meningitis, enteric infection, uraemic syndrome in humans and livestock. ${ }^{20} \mathrm{H}$. pylori belonging to the genus Helicobacter is known to cause chronic gastritis and ulcerations ${ }^{21}$ while K. pneumoniae from the genus Klebsiella causes intra-mammary infections, and Donovanosis (K. granulomatis) as revealed by Umeh and Berkowitz ${ }^{22}$ and Bannerman et al. ${ }^{23} L$. jordanis, $L$. lytica, L. pneumophila and L. sainthelensi from the genus Legionella are known to cause pneumonia, Legionnaire's disease and Pontiac fever ${ }^{24}$ while Leptospira interrogans belonging to the genus Leptospira is known to cause leptospirosis. ${ }^{25}$

The detected $M$. aeruginosa from the genus Microcystis is known to cause poisoning ${ }^{26}$ while $M$. bovis, $M$. tuberculosis and $M$. leprae belonging to the Mycobacterium genus are known to cause tuberculosis and leprosy. ${ }^{27,28}$ Salmonella enterica is known to cause gastroenteritis, enteric fever, osteomyelitis and diarrhoea in humans and livestock ${ }^{29,30}$ while $S$. aureus, S. epidermidis and S. saprophyticus from the genus Staphylococcus are known to cause skin disease, bacteraemia, wound infections, endocarditis, catheter-related sepsis, UTI, toxic shock syndrome, food poisoning, eye infection and osteomyelitis. ${ }^{31,32} T$. pedis and $T$. pallidum from the genus Treponema are known to cause dermatitis and syphilis in humans and livestock. ${ }^{33,34}$

Seasonality of zoonotic bacterial pathogens of public health concern

Brucella spp., Bacillus spp., Chlamydia spp., Enterococcus sp., Legionella spp., Leptospira spp., Mycobacterium spp., Salmonella enterica and Staphylococcus spp. showed a significant difference in abundance between the wet and dry seasons. Brucella spp., Bacillus spp., Chlamydia spp., Enterococcus sp., Legionella spp. and Salmonella enterica had higher abundances in the dry season compared to the wet season, indicating that the exposure of the populace and livestock in Ohangwena and Omusati regions to these species is pronounced in the dry season although disease cases are not documented. It can be argued that since pathogens show seasonality in aquatic environments and correlate with higher temperatures prevailing in the dry, it cannot be ruled out that the warmer temperatures in the wet season can also support the growth of Brucella spp., Bacillus spp., Chlamydia spp., Enterococcus $s p$., Legionella spp. and Salmonella enterica since bacterial species respond quickly to higher temperatures when appropriate resources are available. $^{35}$

Leptospira spp., Mycobacterium spp. and Staphylococcus spp. had higher abundances in the wet season compared to the dry season, demonstrating that exposure to these species is pronounced in the wet season compared to the dry season because of surface runoff. Moreover, these species are mesophilic in nature and so the water temperatures are mostly within their optimal growth or survival range since handdug well water temperature values ranged from $13.2^{\circ} \mathrm{C}$ to $26.3^{\circ} \mathrm{C}$ in the wet season and $20.5^{\circ} \mathrm{C}$ to $34.6^{\circ} \mathrm{C}$ in the dry season which supports the growth of mostly mesophilic bacteria. However, Escherichia coli, Helicobacter spp., Treponema spp. and Klebsiella sp. did not show a significant difference in abundance between the wet and dry seasons demonstrating that the Ohangwena and Omusati rural populace and livestock experience a continuous exposure to these pathogens. This leads to the conclusion that some water related diseases that occur in these communities can be predicted and appropriate prevention measures ascertained based on pathogen's seasonal variations in abundance.

Influence of season on zoonotic bacterial pathogens diversity, evenness and richness

This study revealed a significant difference in the diversity and evenness, and no significant difference in richness of zoonotic bacterial pathogens in hand-dug wells between the wet and dry seasons $(P<0.05)$ with the dry season having a higher diversity and evenness compared to the wet season. The higher diversity in the dry season translates into increased bacterial loads of each detected zoonotic bacterial pathogenic species in these hand-dug wells. The dry season is characteristic of water scarcity with thirsty animals having no access to flowing water as is the case in the rainy season. This compels livestock and other animals or birds to walk into the water in the case 
of shallow hand-dug wells thereby potentially depositing the zoonotic species which can provide a basis for the transfer of enteric zoonotic pathogens between humans and livestock since the hand-dug well water is consumed by both life forms.

The hand-dug wells are poorly constructed in that water is continuously in contact with the soil due to lack of concrete walls and lack top covers. This promotes the survival and unceasing source of soil bacteria, and introduction of enteric microorganisms from animal defecation and this agrees with Ayantobo et al. ${ }^{36}$ who found that unprotected hand-dug wells had the highest $E$. coli and total coliform counts followed by semiprotected hand-dug wells and protected handdug wells. In the case of deep hand-dug wells, the livestock drink water from the troughs that are placed besides the deep hand-dug wells and consequently drop faeces close to the hand-dug wells which can be transported into these wells by wind or water running from the troughs since they lack a top covering. Since Namibia is among countries with the highest rate of open defecation in southern Africa ${ }^{37}$, it's logical that hand-dug wells can be polluted with enteric microorganisms especially in the rainy season when the water penetrates the permeable soil layers reaching the aquifers below that are shared by the hand-dug wells within the same vicinity. ${ }^{38}$

The reason for a high zoonotic bacterial diversity in the dry season is most likely due to increased evaporation of hand-dug well water leading to a reduced volume of water with concentrated bacteria. Odonkor and $\mathrm{Addo}^{2}$ argued that reduced water volumes coupled with increased water-animal contact leads to high bacterial abundance and richness. Hence the soil water exchange interface of bacteria coupled with the effect of evaporation can be viewed as a vicious cycle that potentially maintains the zoonotic bacterial pathogen communities in these handdug wells. The soil water interface can potentiate larger genetic and metabolic plasticity by the transfer and exchange of genes owed to microbial interactions thereby enhancing the ability of the microorganisms to cope with various or fluctuating environmental conditions in the hand-dug wells. Evidently, Escherichia species were known not to survive lengthy periods outside warm blooded animal intestines making them reliable water quality indicators for faecal contamination and predictors of the potential presence of other contaminant species. ${ }^{39}$ However, recent studies have indicated that $E$. coli strains survive in soil and water that's not known to be faecally contaminated. ${ }^{40}$

Overall, the high numbers of detected zoonotic bacterial pathogens are alarming due to possibilities of transferring untreatable bacterial infections between humans and livestock that arise as a result of the inappropriate use of antibiotics in food animals. This leads to untreatable infections when bacteria attain the state of Antimicrobial resistance (AMR). Argudon et al. ${ }^{41}$ revealed that $A M R$ can be transmitted from animals to humans or vice versa either by the direct spread of the resistant bacteria or indirectly through the transmission of resistance genes from animal bacteria to human bacteria. Hence the detection of zoonotic pathogens in hand-dug water used for both humans and livestock consumption also served as a sentinel surveillance deeming these hand-dug wells a possible antimicrobial resistance gene reservoir.

Genetic elements that encode AMR transmission have been documented to exist in commensal bacteria and the intestinal tract is among the core potential sites for the transmission of resistance genes from none pathogenic to pathogenic organisms. ${ }^{10}$ Among the pathogens identified in this study, E. coli is well documented as a potential source and assimilator of AMR plasmids/genes from the environment, and can disseminate genetic determinants thereby serving as a reservoir for transmissible resistance. ${ }^{10}$ Zoonotic pathogens detected in this study known to express multidrug resistance genes include Escherichia, ${ }^{42}$ Klebsiella ${ }^{43}$ Enterobacter ${ }^{44}$ Salmonella,${ }^{45}$ and Pseudomonas.$^{46}$ Hence, the high numbers of zoonotic bacterial pathogens in this study signalled the possible upsurge of antibiotic resistant bacterial strains.

Although Metagenomics is a highly informative technique, it has some limitations that are worth noting when used. Metagenomics as opposed to Metatranscriptomics is a DNA based technique, hence the microbial communities detected potentially included DNA from dead bacteria thereby displaying an over representation 
of bacterial communities or omitted some bacteria due to DNA extraction difficulties especially in spore forming Firmicutes as described by Filippidou et $a .^{47}$ This might have led to a low coverage of less abundant taxa known as "depth bias" and under-representation of certain taxa.

\section{CONCLUSIONS}

The presence of a diverse assemblage of zoonotic pathogens showed that the water was not definitely safe for human consumption and undoubtedly harmful to livestock as well. The exposure of humans and livestock to zoonotic bacterial pathogens is more pronounced in the dry season compared to the wet season. Furthermore, hand-dug wells were found to be a potential reservoir for antimicrobial resistance genes.

\section{ACKNOWLEDGMENTS}

We thank Dr. H. Wanke through SASSCAL for funding this research and the support during field sampling by Josefina Hamutoko and Gabriel Nghikongelwa is gratefully acknowledged.

\section{CONFLICT OF INTERESTS}

The authors declares that there is no conflict of interest.

\section{AUTHOR CONTRIBUTIONS}

BM collected the water samples and performed the research. WNH and BM analysed microbial diversity, richness, evenness and the statistical analysis. BM, WNH, HW, PMC and BMH wrote the manuscript. BM, PMC and $\mathrm{BMH}$ proof read the manuscript.

\section{FUNDING}

This work was funded by Dr. Heike Wanke through SASSCAL through a Doctorate research scholarship.

\section{DATA AVAILABILITY}

The 16S rRNA sequences data that were generated in the current study are available on GenBank, with the following accession numbers: $\mathrm{MH} 155975$ - MH156031.

\section{ETHICS STATEMENT}

This article does not contain any studies with human participants or animals performed by any of the authors.

\section{REFERENCES}

1. World Health Organization, Guidelines for drinkingwater quality: recommendations (Vol. 1). World Health Organization, 2004.

2. Odonkor, S.T. and Addo, K.K., Microbiological Quality of Water Sources from the Largest District in GreaterAccra Region, Ghana: A Call for Innovational Schemes towards Rural Water Resources Management. International Journal of Science, Environment and Technology, 2013; 4: pp.536-555.

3. Park K. Environment and Health in: Park's Textbook of preventive and social medicine, 2002. Christelis, G. and Struckmeier, W. Groundwater in Namibia, an explanation to the Hydrogeological Map. Namibia: Layout and production, 2011.

4. Christelis, G. and Struckmeier, W. Groundwater in Namibia, an explanation to the Hydrogeological Map. Namibia: Layout and production, 2011.

5. Proctor, C.R., Dai, D., Edwards, M.A. and Pruden, A. Interactive effects of temperature, organic carbon, and pipe material on microbiota composition and Legionella pneumophila in hot water plumbing systems. Microbiome, 2017; 5(1): pp.130. https://doi. org/10.1186/s40168-017-0348-5

6. Abinah, S. Assessing the Water Quality of River Asuotia And Six Hand-Dug Wells at Wamfie in the Dormaa East District of Brong Ahafo Region, Ghana (Doctoral dissertation), 2013.

7. Yakubu, S. Assessment of water quality of hand-dug wells in Zaria LGA of Kaduna State, Nigeria. International Journal of Engineering Science, 2013; 2(11): pp.01-04.

8. Alemayehu, A. Review on emerging and re-emerging bacterial zoonotic diseases. American-Eurasian Journal of Scientific Research, 2012; 7(4): pp.176-186.

9. Wand, M.E., McCowen, J.W., Nugent, P.G. and Sutton, J.M. Complex interactions of Klebsiella pneumoniae with the host immune system in a Galleria mellonella infection model. Journal of Medical Microbiology, 2013; 62(12): pp.1790-1798. https://doi. org/10.1099/jmm.0.063032-0

10. Winokur, P.L., Vonstein, D.L., Hoffman, L.J., Uhlenhopp, E.K. and Doern, G.V. Evidence for Transfer of CMY-2 AmpC ג-Lactamase Plasmids between Escherichia coli and Salmonella Isolates from Food Animals and Humans. Antimicrobial Agents and Chemotherapy, 2001; 45(10): pp.2716-2722. https:// doi.org/10.1128/AAC.45.10.2716-2722.2001

11. Capone, K.A., Dowd, S.E., Stamatas, G.N. and Nikolovski, J. Diversity of the human skin microbiome early in life. Journal of Investigative Dermatology, 2011; 131(10): pp.2026-2032. https://doi.org/10.1038/ jid.2011.168

12. DeSantis, T.Z., Hugenholtz, P., Larsen, N., Rojas, M., Brodie, E.L., Keller, K., Huber, T., Dalevi, D., Hu, P. and Andersen, G.L. Greengenes, a chimera-checked $16 \mathrm{~S}$ rRNA gene database and workbench compatible with ARB. Applied and Environmental Microbiology, 2006; 72(7): pp.5069-5072. https://doi.org/10.1128/ 


\section{AEM.03006-05}

13. Tamura, K. and Nei, M. Estimation of the number of nucleotide substitutions in the control region of mitochondrial DNA in humans and chimpanzees. Molecular Biology and Evolution, 1993; 10(3): pp. 512-526.

14. Kumar, S., Stecher, G. and Tamura, K. MEGA 7: Molecular Evolutionary Genetics Analysis version 7.0 for bigger datasets. Molecular Biology and Evolution, 2016; 33(7): pp.1870-1874. https://doi. org $/ 10.1093 / \mathrm{molbev} / \mathrm{msw} 054$

15. Pielou, E.C. Ecological diversity. J. wiley and Sons, New York, 1975.

16. Assenga, J.A., Matemba, L.E., Muller, S.K., Malakalinga, J.J. and Kazwala, R.R. Epidemiology of Brucella infection in the human, livestock and wildlife interface in the Katavi-Rukwa ecosystem, Tanzania. BMC Veterinary Research, 11(1), pp.189. https://doi. org/10.1186/s12917-015-0504-8

17. Logan, N.A., 1988. Bacillus species of medical and veterinary importance. Journal of Medical Microbiology, 2015; 25(3): pp.157-165. https://doi. org/10.1099/00222615-25-3-157

18. Ni, X., Qin, S., Lou, Z., Ning, H. and Sun, X. Seroprevalence and risk factors of Chlamydia infection in domestic rabbits (Oryctolagus cuniculus) in China. Bio. Med. Research International, 2015. https:// doi.org/10.1155/2015/460473

19. Devriese, L.A., Hommez, J., Laevens, H., Pot, B., Vandamme, P. and Haesebrouck, F. Identification of aesculin-hydrolyzing Streptococci, Lactococci, Aerococci and Enterococci from subclinical intramammary infections in dairy cows. Veterinary Microbiology, 1999; 70(1): pp.87-94. https://doi. org/10.1016/S0378-1135(99)00124-8

20. Durso, L.M., Reynolds, K., Bauer Jr, N. and Keen, J.E. Shiga-toxigenic Escherichia coli O157: H7 infections among livestock exhibitors and visitors at a Texas county fair. Vector-Borne and Zoonotic Diseases, 2005; 5(2): pp.193-201. https://doi.org/10.1089/ vbz.2005.5.193

21. Bento-Miranda, M. and Figueiredo, C. Helicobacter heilmannii sensu lato: an overview of the infection in humans. World Journal of Gastroenterology, 2014; 20(47): pp.17779-17787. https://doi.org/10.3748/wjg. v20.i47.17779

22. Umeh, O. and Berkowitz, L.B. Klebsiella infections. eMedicine. com., 2002.

23. Bannerman, D.D., Paape, M.J., Hare, W.R. and Hope, J.C. Characterization of the bovine innate immune response to intramammary infection with Klebsiella pneumoniae. Journal of Dairy Science, 2004; 87(8): pp.2420-2432. https://doi.org/10.3168/jds.S00220302(04)73365-2

24. Fabbi, M., Pastoris, M.C., Scanziani, E., Magnino, S. and Di Matteo, L. Epidemiological and Environmental Investigations of Legionella pneumophila Infection in Cattle and Case Report of Fatal Pneumonia in a Calf. Journal of Clinical Microbiology, 1998; 36(7): pp.19421947.

25. Fabijanski, E. Leptospirosis in cattle, pigs, sheep, goats, horses and humans. Agriculture Notes, State of Victoria, Department of Primary Industries, 2008.

26. Oehrle, S., Rodriguez-Matos, M., Cartamil, M., Zavala, C. and Rein, K.S. Toxin composition of the 2016 Microcystis aeruginosa bloom in the St. Lucie Estuary, Florida. Toxicon, 2017; 138: pp.169-172. https://doi. org/10.1016/j.toxicon.2017.09.005

27. Palmer, M.V., Welsh, M.D. and Hostetter, J.M. Mycobacterial diseases of animals. Veterinary medicine international, 2011. https://doi. org/10.4061/2011/292469

28. Amato, B., Capucchio, T.M., Biasibetti, E., Mangano, E., Boniotti, B.M., Pacciarini, L.M., Migliore, S., Vitale, M., Fiasconaro, M. and Presti, V.D.M.L. Pathology and genetic findings in a rare case of Mycobacterium caprae infection in a sow. Veterinary Microbiology, 2017; 205: pp.71-74. https://doi. org/10.1016/j.vetmic.2017.05.010

29. Zhang, S., Santos, R.L., Tsolis, R.M., Stender, S., Hardt, W.D., Bnumler, A.J. and Adams, L.G. The Salmonella enterica serotype typhimurium effector proteins $\mathrm{SipA}$, SopA, SopB, SopD, and SopE2 act in concert to induce diarrhea in calves. Infection and Immunity, 2002; 70(7): pp.3843-3855. https://doi.org/10.1128/IAl.70.7.38433855.2002

30. Harvey, R.R., Friedman, C.R., Crim, S.M., Judd, M., Barrett, K.A., Tolar, B., Folster, J.P., Griffin, P.M. and Brown, A.C. Epidemiology of Salmonella enterica Serotype Dublin Infections among Humans, United States, 1968-2013. Emerging Infectious Diseases, 2017; 23(9): pp.1493. https://doi. org/10.3201/eid2309.170136

31. Manji, P.L., Antai, S.P. and Jacob, I.O. Incidence of Staphylococcus aureus, coliforms and antibiotic resistant strains of Escherichia coli in rural water supplies in Calabar South Local Government Area. Journal of Public Health and Epidemiology, 2012; 4: pp.230-237. https://doi.org/10.5897/ JPHE12.055

32. Foster, A.P. Staphylococcal skin disease in livestock. Veterinary Dermatology, 2012; 23(4): pp.342-e63. https://doi.org/10.1111/j.1365-3164.2012.01093.x

33. Evans, N.J., Brown, J.M., Demirkan, I., Murray, R.D., Birtles, R.J., Hart, C.A. and Carter, S.D. Treponema pedis $s p$. nov., a spirochaete isolated from bovine digital dermatitis lesions. International Journal of Systematic and Evolutionary Microbiology, 2009; 59(5): pp.987991. https://doi.org/10.1099/ijs.0.002287-0

34. Correa, M.E., Croda, J., de Castro, A.R.C.M., Pompilio, M.A., de Souza, R.O., de Sב Queiroz, J.H.F., da Silva, K.E., Ko, A.I. and Simionatto, S. High Prevalence of Treponema pallidum Infection in Brazilian Prisoners. The American Journal of Tropical Medicine and Hygiene, 2017; 97(4): pp.1078-1084. https://doi. org/10.4269/ajtmh.17-0098

35. Kirchman, D.L. and Rich, J.H. Regulation of bacterial growth rates by dissolved organic carbon and temperature in the equatorial Pacific Ocean. Microbial Ecology, 1997; 33(1): pp.11-20. https://doi. org/10.1007/s002489900003

36. Ayantobo, O. O., Oluwasanya, G. O., Idowu, O. A. and Eruola, A. O. Water Quality Evaluation of Hand-dug Wells in Ibadan, Oyo State, Nigeria. Global Journal of 
Science Frontier Research Agriculture and Veterinary, 2012; 10(13): pp.1-7.

37. Thomas, A. Strengthening post-ODF programming: reviewing lessons from sub-Saharan Africa. Sustainable Sanitation for All: Experiences, Challenges, and Innovations, 2016; pp. 83. https://doi. org/10.3362/9781780449272.004

38. Van der Wal, A. Understanding Groundwater \& Wells in manual drilling. Unicef. http://www. unicef. org/ wash/files/04. pdf., 2008,

39. World Health Organization, Guidelines for Drinkingwater Quality [electronic resource]: incorporating 1st and 2nd addenda, 2008; 1: Recommendations.

40. NandaKafle, G., Seale, T., Flint, T., Nepal, M., Venter, S.N. and Bryzel, V.S. Distribution of Diverse Escherichia coli between Cattle and Pasture. Microbes and Environments, 2017; 32(3): pp.226-233. https://doi. org/10.1264/jsme2.ME17030

41. Argudan, M.A., Deplano, A., Meghraoui, A., Dod'mont, M., Heinrichs, A., Denis, O., Nonhoff, C. and Roisin, S. Bacteria from Animals as a Pool of Antimicrobial Resistance Genes. Antibiotics, 2017; 6(2): pp.12. https://doi.org/10.3390/antibiotics6020012

42. Chen, C.M., Ke, S.C., Li, C.R., Wu, Y.C., Chen, T.H., Lai, C.H., Wu, X.X. and Wu, L.T. High Diversity of Antimicrobial Resistance Genes, Class 1 Integrons, and Genotypes of Multidrug-Resistant Escherichia coli in Beef Carcasses. Microbial Drug Resistance, 2017; 23(7): pp.915-924. https://doi.org/10.1089/mdr.2016.0223

43. Moradigaravand, D., Martin, V., Peacock, S.J. and Parkhill, J. Population Structure of Multidrug-Resistant
Klebsiella oxytoca within Hospitals across the United Kingdom and Ireland Identifies Sharing of Virulence and Resistance Genes with $K$. pneumoniae. Genome Biology and Evolution, 2017; 9(3): pp.574-584. https:// doi.org/10.1093/gbe/evx019

44. Janecko, N., Martz, S.L., Avery, B.P., Daignault, D., Desruisseau, A., Boyd, D., Irwin, R.J., Mulvey, M.R. and Reid-Smith, R.J. Carbapenem-resistant Enterobacter spp. in retail seafood imported from Southeast Asia to Canada. Emerging Infectious Diseases, 2016; 22(9): pp.1675. https://doi.org/10.3201/eid2209.160305

45. Begum, K., Mannan, S.J. and Ahmed, A. Antibiotic Resistance, Plasmids and Integron Profile of Salmonella Species Isolated from Poultry Farm and Patients. Dhaka University Journal of Pharmaceutical Sciences, 2017; 15(2): pp.209-214. https://doi.org/10.3329/dujps. v15i2.30939

46. Magalhaes, M.J.T.L., Pontes, G., Serra, P.T., Balieiro, A., Castro, D., Pieri, F.A., Crainey, J.L., Nogueira, P.A. and Orlandi, P.P. Multidrug resistant Pseudomonas aeruginosa survey in a stream receiving effluents from ineffective wastewater hospital plants. $B M C$ Microbiology, 2016; 16(1): pp.193. https://doi. org/10.1186/s12866-016-0798-0

47. Filippidou, S., Junier, T., Wunderlin, T., Lo, C.C., Li, P.E., Chain, P.S. and Junier, P. Under-detection of endospore-forming Firmicutes in metagenomic data. Computational and Structural Biotechnology Journal, 2015; 13: pp.299-306. https://doi. org/10.1016/j.csbj.2015.04.002 